\title{
VARIATION IN A NATURAL POPULATION OF SCHIZOPHYLLUM COMMUNE
}

\section{VARIATION WITHIN THE EXTREME ISOLATES FOR GROWTH RATE}

\author{
S. WILLIAMS*, M. M. VERMA†, J. L. JINKS and C. M. BRASIER \\ Department of Genetics, University of Birmingham, Birmingham B/5 2TT
}

Received 12.iv.76

\begin{abstract}
SUMMARY
Two extreme dikaryotic isolates chosen from a large sample of a localised population of Schizophyllum commune exhibited a considerable amount of genetical variation for growth rate at the near ambient temperature of $20^{\circ} \mathrm{C}$ and at the higher temperature of $30^{\circ} \mathrm{C}$. The potential variation within these extreme isolates was greater than the variation observed in the whole sample. Regression analysis of the variation in growth rate of the dikaryotic progeny of the extreme isolates on that of their component monokaryons showed that the nature of gene action was not the same in these two stages of the life cycle.

The simple additive-dominance model of gene action was adequate to explain the variation in growth rate in both of the extreme isolates at both of the temperatures. The small deviations from this model could be accounted for by unequal gene frequencies due to small sample size although a low incidence of non-allelic interactions could not be ruled out. Directional dominance for growth rate was detected in both isolates at the more normal temperature and it was opposing in direction in the two isolates. In the slow growing isolate the dominance was for faster growth and in the fast growing isolate it was for slower growth. This is expected for a character which displays overall ambi-directional dominance if isolates with more extreme growth rates than those recovered in the population sample are eliminated by stabilising selection. The dominance is temperature dependent being ambi-directional in both isolates at the higher temperature.

Environmental heterogeneity, the buffering effects of directional dominance and genotype-environment interactions and opposing selective forces operating on the monokaryotic and dikaryotic stages of the life cycle are possible contributory factors to the considerable free and potential variability displayed in this small, localised population.
\end{abstract}

\section{INTRODUCTION}

THE fungi are now being extensively used in the biometrical genetical studies of continuous variation because they offer a number of advantages over the commercially important higher organisms. The application of the biometrical procedures outlined by Simchen and Jinks (1964) and Mather and Jinks (1971) have demonstrated that the phenomena of additivity, dominance and non-allelic interactions exist in the dikaryons of basidiomycetes and behave as in any diploid or amphidiploid organism. These techniques have been mostly applied to study the heritable variation within the progeny of a few dikaryons selected at random from small numbers of wild isolates. They are equally suitable however, for studying the genetical structure of a large

* Present address: Normal College, Bangor, North Wales.

$\uparrow$ Permanent address: Department of Plant Breeding, Punjab Agricultural University, Ludhiana, India.

+ Present address: Forest Research Station, Alice Holt Lodge, Farnham, Surrey, England. 
population as well as for different known segments of a population. In the present study two extreme isolates of a large and genetically variable population of Schizophyllum commune were examined to determine:

(i) the magnitude of the potential variation for growth rate within the extreme isolates;

(ii) the genetical control of growth rate in the extreme segments of the population and

(iii) the shifts, if any, in the control in an altered environment not commonly encountered by the organism.

\section{Materials and methods}

Growth rate and fruiting ability in a random sample of 77 dikaryons of a localised but dense natural population of Schizophyllum commune were studied by Brasier (1970). The materials for the present study are two extreme isolates (designated as isolate 25 and isolate 26) chosen from this population. Isolate 25 had the slowest growth rate under the three temperature conditions studied while isolate 26 had above average growth rate at all temperatures and was one of the fastest at $25^{\circ} \mathrm{C}$ and $30^{\circ} \mathrm{C}$. Both were also chosen for their good and fast fruiting.

From each isolate, six monokaryotic progeny of each of the four incompatibility groups were taken at random and all possible matings were made between them. Thus, among the monokaryotic progeny of each dikaryotic isolate, two $6 \times 6$ series of dikaryotic combinations [designated as $(a-f)(g-l)$ and $(m-r)(s-z)$ series] were formed to give rise to 72 dikaryons derived from all possible combinations among 24 monokaryons. The media used, their preparation and composition have been described by Simchen (1965). The techniques of isolation, fruiting and raising of the progeny as well as the measurement of growth rate and biometrical procedures follow closely those of Simchen and Jinks (1964) and Simchen (1966). Two incubators, one at $20^{\circ} \mathrm{C}$ and the other at $30^{\circ} \mathrm{C}$ were used in the determination of growth rate. Each of the three shelves of an incubator contained one randomised block and each block contained 97 randomised growth tubes (one tube each of the original dikaryon, 24 monokaryons and 72 dikaryons).

In addition, regression analysis of genotype $\times$ environment interaction was carried out as suggested by Perkins and Jinks (1968). However, in this analysis it was used to analyse genotype $\times$ genotype interactions, one set of monokaryons say $(a-f)$ being considered as the variable environments for the second set of monokaryons $(g-l)$ and vice versa.

Directional dominance can be detected directly by comparing the means of each pair of monokaryons and their $\mathbf{F}_{\mathbf{1}}$ dikaryon (Mather and Jinks, 1971) and on averaging over all pairs and their $F_{1}$ 's it indicates the net directional dominance in the population. This comparison, however, measures directional dominance only if we assume that all differences in gene action between the dikaryotic and monokaryotic states can be attributed to dominance and that there are no differences in gene action per se between these two alternative states. This assumption does not appear to hold in general (Simchen and Jinks, 1964) or in these data. While, therefore, we shall compare the growth rates of monokaryotic parents and their $\mathbf{F}_{\mathbf{1}}$ dikaryons they are not used to determine the direction of dominance. 


\section{Results}

(i) Genetic variation for growth rate

The analysis of variance in respect of growth rate of the dikaryotic progeny of the two isolates at $20^{\circ} \mathrm{C}$ and $30^{\circ} \mathrm{C}$ is presented in tables 1 and 2 . The significant differences among the dikaryons in both duplicate series of both the isolates in each environment suggests the existence of genetic

TABLE 1

Analysis of variance of growth rate in two duplicate series of two isolates under normal and high temperature conditions

\begin{tabular}{|c|c|c|c|c|c|c|c|}
\hline \multirow[b]{3}{*}{ Isolate } & \multirow[b]{3}{*}{ Item } & \multirow[b]{3}{*}{ d.f. } & \multicolumn{5}{|c|}{ Mean squares } \\
\hline & & & \multicolumn{3}{|c|}{$20^{\circ} \mathrm{C}$} & \multicolumn{2}{|c|}{$30^{\circ} \mathrm{C}$} \\
\hline & & & Series: & $(a-f)(g-l)$ & $(m-r)(s-z)$ & $(a-f)(g-l)$ & $(m-r)(s-z)$ \\
\hline \multirow[t]{3}{*}{25} & Blocks & 2 & & $3 \cdot 20$ & $3 \cdot 30$ & $346 \cdot 00 * *$ & $157 \cdot 00^{*}$ \\
\hline & Dikaryons & 35 & & $35 \cdot 30 * * *$ & $31 \cdot 50 * * *$ & $760 \cdot 20 * * *$ & $791 \cdot 50 * * *$ \\
\hline & Error & 70 & & $4 \cdot 27$ & $4 \cdot 25$ & $63 \cdot 29$ & $42 \cdot 54$ \\
\hline \multirow[t]{3}{*}{26} & Blocks & 2 & & $18 \cdot 30$ & $7 \cdot 20$ & $92 \cdot 20$ & $47 \cdot 15$ \\
\hline & Dikaryons & 35 & & $93.50 * * *$ & $42 \cdot 70 * * *$ & $765 \cdot 80 * * *$ & $376 \cdot 90 * * *$ \\
\hline & Error & 70 & & $11 \cdot 04$ & $13 \cdot 45$ & $40 \cdot 41$ & $39 \cdot 39$ \\
\hline
\end{tabular}

$*, * *, * * *$ Probability less than $0 \cdot 05,0.01$ and 0.001 respectively.

TABLE 2

(a) Pooled analysis of variance over duplicate series for growth rate of two isolates under normal and high temperature conditions

\begin{tabular}{|c|c|c|c|c|c|}
\hline \multirow[b]{3}{*}{ Item } & \multirow[b]{3}{*}{ d.f. } & \multicolumn{4}{|c|}{ Mean squares } \\
\hline & & \multicolumn{2}{|c|}{ Isolate 25} & \multicolumn{2}{|c|}{ Isolate 26} \\
\hline & & $20^{\circ} \mathrm{C}$ & $30^{\circ} \mathrm{C}$ & $20^{\circ} \mathrm{C}$ & $30^{\circ} \mathrm{C}$ \\
\hline ks within series & 4 & $3 \cdot 2500$ & $251 \cdot 5000$ & $12 \cdot 7500$ & $69 \cdot 6750$ \\
\hline een series & 1 & $53 \cdot 0046$ & $44 \cdot 4629$ & $196 \cdot 4629$ & $67 \cdot 7824$ \\
\hline ryons within series & 70 & $33.4000 * * *$ & $775 \cdot 8500 * * *$ & $68 \cdot 1000 * * *$ & $571 \cdot 3500 * * *$ \\
\hline & 140 & $4 \cdot 2500$ & $52 \cdot 9000$ & $12 \cdot 2000$ & 39.9000 \\
\hline
\end{tabular}

(b) Pooled analysis of variance over duplicates and temperatures Blocks within series
within temp.

Between series

Between temperatures

Series $\times$ temperature

Dikaryons within series 140 within temp.

Error

\section{8}

1

1

40

280

$127 \cdot 3750$
$97 \cdot 2801$
$182821 \cdot 2245^{* * *}$
$0 \cdot 1875$
$404 \cdot 6250 * * *$
$28 \cdot 5750$

$41 \cdot 2125$

$247 \cdot 5209$

$247537 \cdot 6875 * * *$

16.7245

$319 \cdot 7250 * * *$

$26 \cdot 0500$

diversity for growth rate. The variation between duplicate series within each isolate when tested against the variation between dikaryons within the series was not statistically significant (table $2 a$ ) suggesting that the duplicates could be considered together. The pooled analysis over duplicates and temperatures (table $2 \mathrm{~b}$ ) revealed that the variation in temperature had a 
tremendous effect on growth rate of both of the isolates and that the duplicates within an isolate did not interact with the temperature. The total genetic variation present in each duplicate series was partitioned into additive, non-additive and the environmental components (tables 3 and 4). The differences due to common parents were significant for six out of eight possible cases for each of the two isolates suggesting the presence of additive variation for growth rate. The highly significant interaction item for all the

TABLE 3

Partitioning of variation between dikaryotic combinations in duplicate series of two isolates

\begin{tabular}{|c|c|c|c|c|c|c|}
\hline \multirow[b]{3}{*}{ Isolate } & \multirow[b]{3}{*}{ Item } & \multirow[b]{3}{*}{ d.f. } & \multicolumn{4}{|c|}{ Mean squares } \\
\hline & & & \multicolumn{2}{|c|}{$20^{\circ} \mathrm{C}$} & \multicolumn{2}{|c|}{$30^{\circ} \mathrm{C}$} \\
\hline & & & $(a-f)(g-l)$ & $(m-r)(s-z)$ & $(a-f)(g-l)$ & $(m-r)(s-z)$ \\
\hline \multirow[t]{4}{*}{25} & Common parents & 5 & $159 \cdot 30 * * *$ & $68 \cdot 40 * *$ & $881 \cdot 40$ & $1720 \cdot 40 *$ \\
\hline & Common parents & 5 & $34 \cdot 10 *$ & $88 \cdot 40 * * *$ & $2019 \cdot 10 * *$ & $890 \cdot 20$ \\
\hline & Parents interaction & 25 & $10 \cdot 66 * *$ & $12 \cdot 87 * * *$ & $484 \cdot 20 * * *$ & $586 \cdot 01 * * *$ \\
\hline & Error & 70 & $4 \cdot 27$ & $4 \cdot 25$ & $63 \cdot 29$ & $42 \cdot 54$ \\
\hline \multirow[t]{4}{*}{26} & Common parents & 5 & $195 \cdot 00^{* *}$ & $73 \cdot 00$ & $1550 \cdot 10^{* *}$ & $982 \cdot 30^{*}$ \\
\hline & Common parents & 5 & $218 \cdot 50 * *$ & $81 \cdot 50 *$ & $1916 \cdot 70 * *$ & $163 \cdot 10$ \\
\hline & Parents interaction & 25 & $48 \cdot 24 * * *$ & $28 \cdot 84 * *$ & $378 \cdot 73 * * *$ & $298 \cdot 59 * * *$ \\
\hline & Error & 70 & $11 \cdot 04$ & $13 \cdot 45$ & $40 \cdot 41$ & $39 \cdot 39$ \\
\hline
\end{tabular}

TABLE 4

Components of variation for growth rate of two isolates under normal and high temperature conditions

\begin{tabular}{|c|c|c|c|c|c|c|}
\hline \multirow[b]{2}{*}{ Isolate } & \multirow[b]{2}{*}{ Temperature } & \multirow[b]{2}{*}{ Series } & \multicolumn{3}{|c|}{ Components } & \multirow{2}{*}{$\begin{array}{c}\text { Total } \\
\text { variance }\end{array}$} \\
\hline & & & Environmental & Non-additive & Additive & \\
\hline 25 & $20^{\circ} \mathrm{C}$ & $\begin{array}{l}(a-f)(g-l) \\
(m-r)(s-z)\end{array}$ & $\begin{array}{l}4 \cdot 27(26 \cdot 75) \\
4 \cdot 25(29 \cdot 49)\end{array}$ & $\begin{array}{l}2 \cdot 13(13 \cdot 35) \\
2 \cdot 87(20 \cdot 00)\end{array}$ & $\begin{array}{l}9.55(59 \cdot 90) \\
7 \cdot 28(50 \cdot 55)\end{array}$ & $\begin{array}{l}15 \cdot 96 \\
14 \cdot 40\end{array}$ \\
\hline \multirow{3}{*}{26} & $30^{\circ} \mathrm{C}$ & $\begin{array}{l}(a-f)(g-l) \\
(m-r)(s-z)\end{array}$ & $\begin{array}{l}63.29(20 \cdot 35) \\
42 \cdot 54(14 \cdot 01)\end{array}$ & $\begin{array}{c}140 \cdot 31(45 \cdot 12) \\
181 \cdot 16(59 \cdot 67)\end{array}$ & $\begin{array}{r}107 \cdot 35(34 \cdot 53) \\
79 \cdot 92(26 \cdot 32)\end{array}$ & $\begin{array}{l}310 \cdot 93 \\
303 \cdot 62\end{array}$ \\
\hline & $20^{\circ} \mathrm{C}$ & $\begin{array}{l}(a-f)(g-l) \\
(m-r)(s-z)\end{array}$ & $\begin{array}{l}11.04(26.90) \\
13.45(56 \cdot 12)\end{array}$ & $\begin{array}{r}12 \cdot 40(30 \cdot 20) \\
5 \cdot 13(21 \cdot 43)\end{array}$ & $\begin{array}{r}17 \cdot 61(42 \cdot 90) \\
5 \cdot 38(22 \cdot 45)\end{array}$ & $\begin{array}{l}41 \cdot 06 \\
23 \cdot 96\end{array}$ \\
\hline & $30^{\circ} \mathrm{C}$ & $\begin{array}{l}(a-f)(g-l) \\
(m-r)(s-z)\end{array}$ & $\begin{array}{l}40 \cdot 41(13 \cdot 31) \\
39 \cdot 39(25 \cdot 21)\end{array}$ & $\begin{array}{r}112.77(37.13) \\
86.40(55.30)\end{array}$ & $\begin{array}{r}150.51(49.56) \\
30.46(19.49)\end{array}$ & $\begin{array}{l}303 \cdot 70 \\
156 \cdot 26\end{array}$ \\
\hline
\end{tabular}

comparisons reflected the importance of non-additive genetic variation determining growth rate under both temperature conditions in both isolates. The estimates of components of variation determined from the mean squares in this analysis were in good agreement for isolate 25 but not for isolate 26. At $20^{\circ} \mathrm{C}$, isolate 26 exhibited higher variation than isolate 25 . However, at the higher temperature, the total variation in isolate 25 was similar to that in isolate 26 [with the exception of the series $(m-r)(s-z)$ ]. In isolate 25, the additive component was larger than the non-additive component at $20^{\circ} \mathrm{C}$ but it was smaller at $30^{\circ} \mathrm{C}$. The ratio of the non-additive to the additive component was relatively larger in isolate 26 than in isolate 25 under both temperature conditions. 
The relative importance of the linear and the non-linear components of variation in the two isolates can also be demonstrated by an alternative technique of regression analysis. The interaction component between the two sets of parents (genotype-genotype interaction) can be partitioned in two ways i.e. considering the interaction of one set of monokaryons $(a-f)$ with the genetic environments of another set of monokaryons $(g-l)$ and vice versa. The results of such analyses are presented in table 5 . For isolate 25 at $20^{\circ} \mathrm{C}$,

TAble 5

Partitioning of the parents (genotype-genotype) interaction

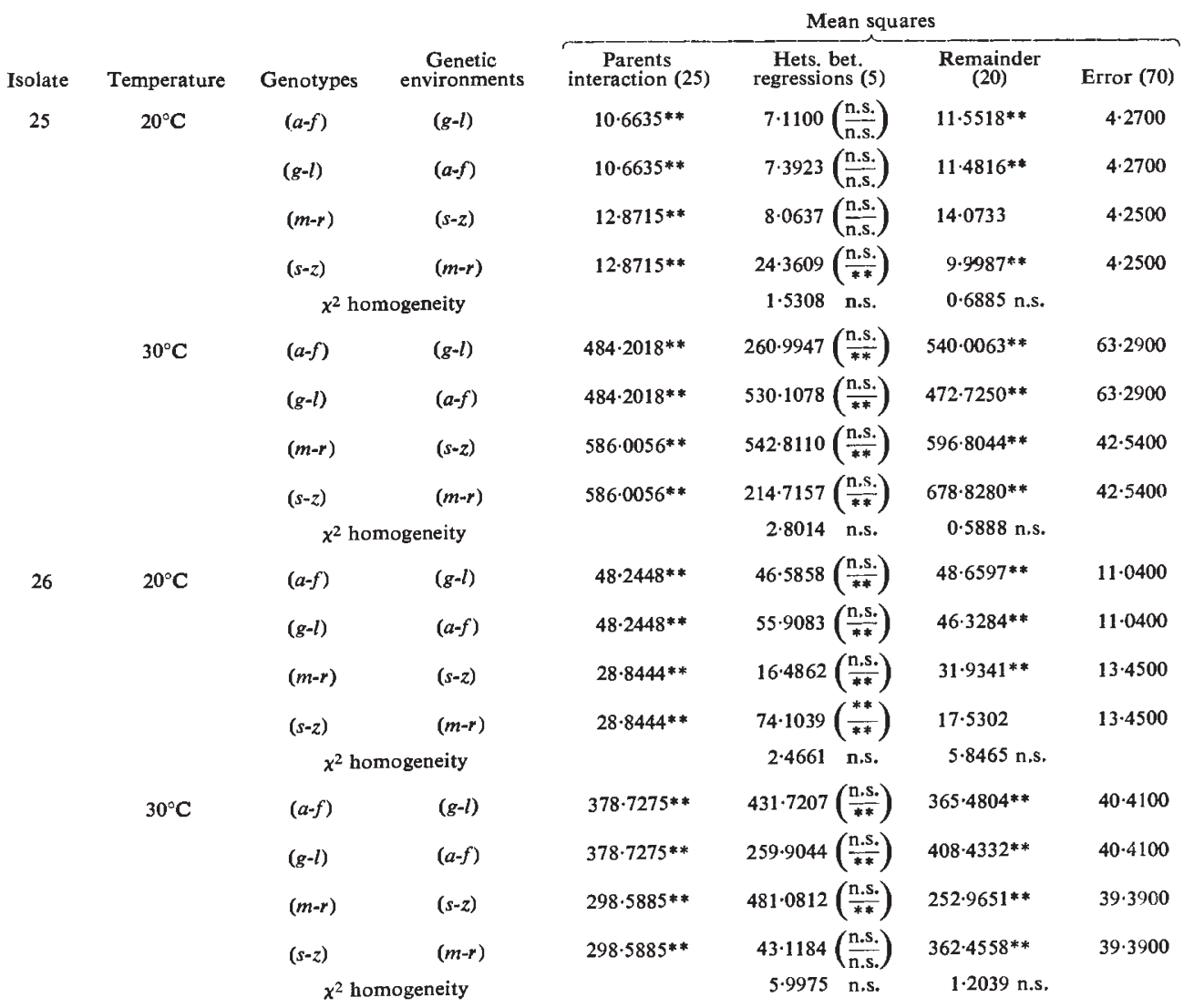

Degrees of freedom are given in parentheses. Heterogeneity between regressions M.S. has been tested against remainder M.S. and error M.S. (upper and lower probabilities respectively). n,s.= not significant.

the heterogeneity between regressions component was not significant when tested against the error variance in three out of four cases and in all cases when tested against the remainder. However, at $30^{\circ} \mathrm{C}$, this linear component became significant in all the four cases when tested against the error. The linear and the non-linear components of the interaction were statistically of the same magnitude. For isolate 26, the linear component was highly significant at both the temperatures when tested against the error variance but was not significant in seven out of eight cases when tested against the 
remainder which was itself highly significant (except in one case). Statistically, these two components were of the same magnitude.

\section{(ii) Non-additive component}

The nature of the non-additive or non-linear component was further investigated by plotting the variances within arrays against covariances between crosses within each array and the array means of the non-common parents. The slopes of the $W^{\prime} r / V r$ graphs were calculated and are presented in table 6.

TABLE 6

Regression slopes of $\mathrm{W}^{\prime} \mathrm{r} / \mathrm{Vr}$ analysis in duplicate series of two isolates for growth rate under normal and high temperature

\begin{tabular}{|c|c|c|c|c|c|c|}
\hline \multirow[b]{2}{*}{ Isolate } & \multirow[b]{2}{*}{ Temperature } & \multicolumn{5}{|c|}{$b W^{\prime} r . V r$} \\
\hline & & $(a-f)$ & $(g-l)$ & $(m-r)$ & $(s-z)$ & Pooled \\
\hline 25 & $\begin{array}{l}20^{\circ} \mathrm{C} \\
30^{\circ} \mathrm{C}\end{array}$ & $\begin{array}{l}0 \cdot 2601^{*+} \\
0.4751^{*}\end{array}$ & $\begin{array}{l}0 \cdot 3549 * \\
0 \cdot 2207\end{array}$ & $\begin{array}{l}0 \cdot 3170^{* *+} \\
0 \cdot 2797^{* *+}\end{array}$ & $\begin{array}{l}0 \cdot 4392 * * \\
0 \cdot 1116\end{array}$ & $\begin{array}{l}0.5321 * * \\
0 \cdot 3179 * *+\end{array}$ \\
\hline 26 & $\begin{array}{l}20^{\circ} \mathrm{C} \\
30^{\circ} \mathrm{C}\end{array}$ & $\begin{array}{l}0.4917 * \\
0.4383 *\end{array}$ & $\begin{array}{l}0 \cdot 3185^{*} \\
0 \cdot 3001^{* *+}\end{array}$ & $\begin{array}{l}0 \cdot 2442^{*+} \\
0 \cdot 1267^{+}\end{array}$ & $\begin{array}{l}0.3544 * \\
0 \cdot 0575\end{array}$ & $\begin{array}{l}0 \cdot 4087 * * \\
0 \cdot 4391 * *\end{array}$ \\
\hline
\end{tabular}
tively).

*,** Regression coefficient significantly different from zero $(\mathrm{P}<0.05$ and 0.01 respec-

+ Regression coefficient significantly different from $0.5(\mathrm{P}<0 \cdot 05)$.

At $20^{\circ} \mathrm{C}$ the regression coefficient was statistically different from zero for both the isolates but it deviated from the expected value of 0.5 in three out of eight cases. However, at $30^{\circ} \mathrm{C}$ the regression coefficient did not differ from zero in half of the cases in respect of both the isolates and there was poor agreement between the duplicate series within an isolate. The pooled estimates over series within each isolate revealed that the simple additivedominance model explained the total variation for growth rate of the dikaryons at $20^{\circ} \mathrm{C}$ for both the isolates and for isolate 26 at $30^{\circ} \mathrm{C}$ as well. For isolate 25, the significant departure of the regression coefficient from the expected value of 0.5 at $30^{\circ} \mathrm{C}$ may be due either to the presence of nonallelic interactions, or unequal gene frequencies at the loci controlling growth rate arising from small sample size.

\section{(iii) Directional dominance}

Directional dominance is indicated by the significant correlation between the $W^{\prime} r+V r$ values of the arrays and the corresponding array mean (mean of the dikaryotic progeny in the array) and the sign of the correlation is determined by whether the increasing or the decreasing alleles are more frequently dominant. At $20^{\circ} \mathrm{C}$, this correlation was consistently negative in all the four independent samples in isolate 25 but positive (except one case) in isolate 26 (table 7). Individually, these correlations were statistically nonsignificant (each based on 4 d.f.). However, these correlations were found to be homogeneous for each isolate and the average correlations $(-0.6126$ for isolate 25 and +0.5908 for isolate 26) were significant. The upper and 
lower 99 per cent confidence limits of these average correlations had negative and positive signs for isolates 25 and 26 respectively and there was no overlapping of these confidence limits. This suggests that on a net balance, there is a directional element to the dominance in both the isolates at $20^{\circ} \mathrm{C}$ and it is in opposite directions in the two isolates. In the slow growing isolate 25, dominance tends to increase the growth rate at the lower temperature whereas in the fast-growing isolate 26 , it tends to decrease the growth rate. Under high temperature conditions, this directional dominance not only disappears but also appears to be reversed. However, the degree of reversal was not sufficient to be detected at a significant level. It has, therefore, to be regarded as ambi-directional dominance.

\section{Discussion}

Under natural conditions, the monokaryotic and the dikaryotic stages coexist in the same habitat at the same time in the life cycle of $S$. commune. The monokaryotic stage while capable of prolonged vegetative growth is a temporary one in the sense that it terminates as soon as the two compatible monokaryons meet. On the other hand, the dikaryon has to produce a certain minimum growth before the formation of fruiting bodies. A very

TABle 7

Directional dominance as indicated by the correlation between $\mathrm{W}^{\prime} \mathrm{r}+\mathrm{Vr}$ and array mean of dikaryotic descendants

\begin{tabular}{|c|c|c|c|c|c|c|c|c|}
\hline \multirow[b]{2}{*}{ Isolate } & \multirow[b]{2}{*}{ Temperature } & \multicolumn{7}{|c|}{$r\left(W^{\prime} r+V r\right)$. Array mean } \\
\hline & & $(a-f)$ & $(g-l)$ & $(m-r)$ & $(s-z)$ & $\begin{array}{c}\chi^{2} \text { for } \\
\text { homogeneity }\end{array}$ & Average & $\begin{array}{l}99 \% \text { confidence limits } \\
\text { of average }\end{array}$ \\
\hline 25 & $\begin{array}{l}20^{\circ} \mathrm{C} \\
30^{\circ} \mathrm{C}\end{array}$ & $\begin{array}{r}-0.5214 \\
0.4936\end{array}$ & $\begin{array}{r}-0 \cdot 7268 \\
0 \cdot 1701\end{array}$ & $\begin{array}{r}-0.7320 \\
0.3072\end{array}$ & $\begin{array}{r}-0.3961 \\
0.2498\end{array}$ & $\begin{array}{l}0.75<P>0.09 \\
0.95<P>0.975\end{array}$ & $\begin{array}{c}-0.6126^{*} \\
0.3107\end{array}$ & $\begin{array}{rr}-0.069 \text { to } & -0.875 \\
-0.312 \text { to } & 0.747\end{array}$ \\
\hline 26 & $\begin{array}{l}20^{\circ} \mathrm{C} \\
30^{\circ} \mathrm{C}\end{array}$ & $\begin{array}{l}0.6639 \\
0.2635\end{array}$ & $\begin{array}{r}0.5973 \\
-0.1027\end{array}$ & $\begin{array}{r}0.8418 \\
-0.7551\end{array}$ & $\begin{array}{l}-0.0004 \\
-0.5330\end{array}$ & $\begin{array}{l}0.50<P>0.75 \\
0.25<P>0.50\end{array}$ & $\begin{array}{l}0.5908^{*} \\
-0.3391\end{array}$ & $\begin{array}{l}0.035 \text { to } 0.867 \\
0.283 \text { to }-0.760\end{array}$ \\
\hline
\end{tabular}

fast-growing dikaryon is expected to cover a large area and is likely to produce more fruiting bodies provided the food resources are not limiting. In the event of limited resources due to competition with the other dikaryons and monokaryons in the population, a very fast-growing dikaryon may utilise the available nutrients for its growth leaving little for the formation of fruiting bodies. So natural selection is likely to favour mediocre genotypes at the expense of extremes. This type of natural selection has been referred to as stabilising selection (Mather, 1953).

The two isolates with extreme growth rate exhibited large differences in

TABLE 8

Relative distribution of dikaryons in relation to parental monokaryons

$\begin{array}{ccccc}\text { Isolate } & \text { Temperature } & \begin{array}{c}\text { Faster than } \\ \text { both parents }\end{array} & \text { Intermediate } & \begin{array}{c}\text { Slower than } \\ \text { both parents }\end{array} \\ 25 & 20^{\circ} \mathrm{C} & 7 & 32 & 33 \\ 26 & 20^{\circ} \mathrm{C} & 43 & 21 & 8 \\ 25 & 30^{\circ} \mathrm{C} & 43 & 21 & 8 \\ 26 & 30^{\circ} \mathrm{C} & 54 & 16 & 2\end{array}$


growth rate under both temperature conditions. There was a considerable genetic variation for growth rate within each isolate which suggested that growth rate is not a neutral character but has adaptive significance. At the lower temperature which is nearer to that found in the natural environment, the two isolates also differed in the rate of growth of the dikaryons in relation to the parental monokaryons. The relative frequency of the faster-growing, intermediates and the slower-growing dikaryons (table 8) was not the same in the two isolates $\left(\chi^{2}=43.45\right.$ for 2 d.f.). This distribution remained constant for isolate 26 at both the temperatures $\left(\chi^{2}=5.52\right.$ for 2 d.f.) but it differed for isolate 25 ( $\chi^{2}=28 \cdot 61$ for 2 d.f.). The dikaryons of isolate 25

TABLE 9

Correlations between deviations from linear regression at $20^{\circ} \mathrm{C}$ and $30^{\circ} \mathrm{C}$

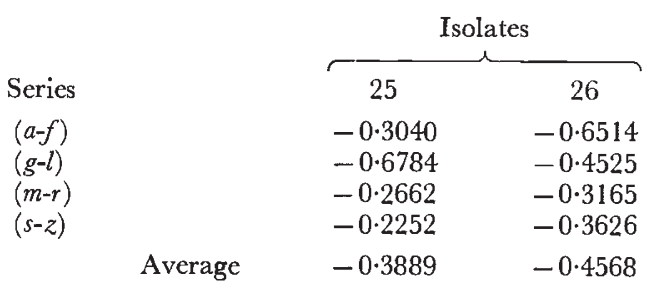

TABLE 10

Regression analysis of growth rate of dikaryons on mid-parental value of monokaryons

\begin{tabular}{|c|c|c|c|c|c|}
\hline \multirow[b]{2}{*}{ Temperature } & \multirow[b]{2}{*}{ Isolate } & \multirow[b]{2}{*}{ Series } & \multicolumn{3}{|c|}{ Mean squares } \\
\hline & & & Regression (1) & Remainder (34) & Error (70) \\
\hline $20^{\circ} \mathrm{C}$ & 25 & $\begin{array}{l}(a-f)(g-l) \\
(m-r)(s-z) \\
(a-f)(g-l) \\
(m-r)(s-z)\end{array}$ & $\begin{array}{c}602 \cdot 4 * * \\
97 \cdot 9 \\
2149 \cdot 3 * * \\
193 \cdot 3 * *\end{array}$ & $\begin{array}{r}77 \cdot 9 * * * \\
81 \cdot 1 * * * \\
241 \cdot 2 * * * \\
35 \cdot 5 * * *\end{array}$ & $\begin{array}{r}4 \cdot 3 \\
4 \cdot 2 \\
11 \cdot 0 \\
13 \cdot 4\end{array}$ \\
\hline $30^{\circ} \mathrm{C}$ & $\begin{array}{l}25 \\
26\end{array}$ & $\begin{array}{l}(a-f)(g-l) \\
(m-r)(s-z) \\
(a-f)(g-l) \\
(m-r)(s-z)\end{array}$ & $\begin{array}{c}2523 \cdot 6 * * \\
47 \cdot 4 \\
3622 \cdot 2 \\
972 \cdot 5\end{array}$ & $\begin{array}{r}222 \cdot 5 * * * \\
1123 \cdot 2 * * * \\
932 \cdot 9 * * * \\
490 \cdot 9 * * *\end{array}$ & $\begin{array}{l}63 \cdot 3 \\
42 \cdot 5 \\
40 \cdot 4 \\
39 \cdot 4\end{array}$ \\
\hline
\end{tabular}

were in general slower growers than the parental monokaryons. On the other hand, the dikaryons of isolate 26 were generally faster in growth, and did not differ significantly from the growth rate of their faster monokaryotic parent. However, with the abrupt change in the environment (high temperature), there was a tremendous increase in the growth rate of monokaryons as well as dikaryons of both the isolates. The dikaryons grew faster than their faster-growing parent for both isolates except for one duplicate set of isolate 25.

In the genotype-genotype interaction analysis the non-linear component was highly significant for both isolates in both temperature environments. More important, however, the direction of this component tended to be reversed between the two environments. Indeed, the correlations for this component between the two environments while non-significant were 
consistently negative (table 9). This strongly suggests that the direction of the non-additive gene action is reversed between the two environments.

The nature of the non-additive component was investigated by regressing the covariances between crosses within each array and the array means of non-common parents $\left(W^{\prime} r\right)$ on to the variances within arrays $(V r)$. The fact that at the lower, nearer ambient temperature, the pooled regression over duplicate sets in both the isolates was highly significant and did not differ from the expected value of 0.5 suggested that the departures from the expected regression slope observed in different series within both the isolates were due solely to unequal gene frequencies presumably resulting from small sample size. Under the higher temperature conditions, however, the simple additive-dominance model failed to account for the variation even after pooling over duplicates in isolate 25 suggesting the presence of non-allelic interactions in addition to dominance. Brasier (1970) provided evidence that growth rate may be subject to control by different loci at different temperatures. Simchen and Jinks (1964) reported that the relationship between growth rate of a dikaryon and its parental monokaryons depends on the genotypic constitution of the component monokaryons and not on the dikaryotic state per se. The fact that the frequency of the dikaryons with slow, intermediate or fast growth relative to the parental monokaryons changed at different temperatures for isolate 25 whereas it was independent of the temperature in isolate 26 suggests a significant shift in the non-additive gene action in isolate 25 between the two temperatures.

This could involve either a change in the kind of gene action or a change in the relative contributions of genes at the same set or at a different set of loci at the two temperatures. It is possible, therefore, that the expectation of equal gene frequencies could be met at $20^{\circ} \mathrm{C}$ but could fail in the sample of monokaryons at $30^{\circ} \mathrm{C}$. With this as a possibility it is not necessary to conclude that non-allelic interactions must be responsible for the failure of the $W^{\prime} r, V r$ relationship at $30^{\circ} \mathrm{C}$. Previous studies also support the view that dominance alone accounts for the non-linear component for growth rate (Simchen and Jinks, 1964; Simchen, 1966; Connolly and Jinks, 1975).

There is sufficient evidence that in general, dominance for growth rate in S. commune is ambi-directional (Simchen and Jinks, 1964; Simchen, 1966). The opposing directional dominance displayed by the dikaryotic progeny of isolates 25 and 26 must mean therefore, that these extreme isolates from the population are heterozygous at a highly selected sample of loci. The heterozygosity in the slow growing isolate (25) must be largely confined to loci at which the increasing alleles are dominant while in the fast growing isolates (26) it must be largely confined to the loci at which the decreasing alleles are dominant. For example, if we assume that isolates 25 and 26 differ at eight loci, four of which have increasing alleles (A, B, G and D) dominant to their decreasing alleles $(a, b, c$ and $d)$ and four have decreasing alleles $(w, x, y$ and $z$ ) dominant to their increasing alleles $(W, X, Y$ and $Z$ ) then on this model appropriate genotypes for isolates 25 and 26 might be:

isolate $25 A a B b C c d d w w x x y$ y $z z$

(phenotype: 3 increasing loci, 4 decreasing loci)

isolate $26 A A B B C C D d W w X x r y z Z$

(phenotype: 5 increasing loci, 3 decreasing loci) 
Isolate 25, while being the slowest growing in the population sample of 77 isolates, is expected on this model to grow as fast or faster than 98 per cent (faster than 76 per cent) of all possible isolates heterozygous at the same number of randomly chosen loci while remaining homozygous for the decreasing allele at the other four loci. Similarly, isolate 26, while being one of the faster growing isolates in the population sample, is expected on this same model to grow as slow or slower than 98 per cent of all possible isolates heterozygous at the same number of randomly chosen loci while remaining homozygous for the increasing allele at the other four loci. Thus dikaryons that are more extreme in rate of growth than 25 and 26 must continually arise in the population, as a result of the compulsory outcrossing followed by segregation, at frequencies well in excess of isolates which like 25 and 26 must be heterozygous at a restricted set of loci. Indeed such segregants arise in the dikaryotic progenies derived from isolates 25 and 26. Their absence from the extreme segments of the population sample, therefore, must mean that they are selectively eliminated from the population because of their extreme phenotypes. Thus the directional dominance towards intermediate growth rates displayed by the extreme phenotypes which have survived to be represented in the sample is a predictable consequence of stabilising selection on a character displaying an overall ambidirectional dominance. The directional dominance displayed by these extreme phenotypes is in no way in conflict with the expectation that low or ambi-directional dominance is the result of a past history of stabilising selection and directional dominance of a past history of directional selection (Mather, 1953, 1960, 1973; Jinks, 1954; Breese and Mather, 1957; Jinks and Broadhurst, 1963; Lawrence, 1965; Barnes, 1966, 1968; Kearsey and Kojima, 1967; Kearsey and Barnes, 1970).

The mechanism of directional dominance operating in the two isolates seems to be temperature-dependent because ambi-directional dominance was observed in both the isolates at the higher unfamiliar temperature. In the population from which the isolates were obtained, the genetical system regulating rate of growth has been evolving at temperatures that are nearer to $20^{\circ} \mathrm{C}$ than $30^{\circ} \mathrm{C}$ and for most of the time below $20^{\circ} \mathrm{C}$. Growth at $30^{\circ} \mathrm{C}$, therefore, involved an abrupt change in the environment that might be expected to affect and even disrupt this regulatory system. However, although the increase in temperature had a tremendous effect on growth rate, there is no compelling evidence that the simple additive-dominance model of gene action was inadequate at this temperature. It could be argued that if directional dominance has a role in stabilising growth rate at some intermediate optimum, then at the higher temperature, uni-directional dominance favouring slow growth should appear in isolate 25 and the unidirectional dominance favouring slow growth already present in isolate 26 should become more intense. Such uni-directional dominance, however, will not manifest itself in the same generation in which the genetical system is exposed to higher temperatures unless the necessary dominance modifiers are already present and since the evolution of dominance is a long-term process, these modifiers will be present in the population only if it has been regularly exposed to high temperatures or to other environmental factors that evoke equivalent responses in the phenotype.

There is evidence that most of the genetic variation for growth rate of dikaryons is not correlated with the variation in monokaryons (Simchen and 
Jinks, 1964). In this study as well, the regression analysis of growth rate of the dikaryotic descendants on their parental monokaryons revealed that the regression mean squares when tested against the remainder were significant only in some of the duplicate sets (table 10). However, a significant part of the variation in growth at $20^{\circ} \mathrm{C}$ can be accounted for by the variation in the monokaryotic parents but the remainder mean squares were always significant at both the temperatures in both the isolates indicating that a major part of the variation in the growth of dikaryons is not related to the variation in the monokaryons. It clearly brings out the fact that the nature of gene action is not the same in the two stages and presumably the selective forces acting on them are correspondingly different.

Acknowledgments.- - One of us (M. M. V.) was supported by the Commonwealth Academic Staff Fellowship awarded by the Association of Commonwealth Universities.

\section{REFERENCES}

BARnes, B. W. 1966. Environment and selection in Drosophila melanogaster. Ph.D. Thesis, University of Birmingham, England.

Barnes, B. w. 1968. Stabilising selection in Drosophila melanogaster. Heredity, 23, 433-442. BRASIER, C. M. 1970. Variation in natural population of Schizophyllum commune. Amer. Nat., 104, 191-204.

BREeSE, E. L., AND MATHER, K. 1957. The organisation of polygenic activity within a chromosome in Drosophila. I. Hair characters. Heredity, 11, 373-395.

CONNOLLY, V., AND JINKs, J. L. 1975. The genetical architecture of general and specific environmental sensitivity. Heredity, 35, 249-259.

JINKS, J. L. 1954. The analysis of continuous variation in a diallel cross of Nicotiana rustica varieties. I. The analysis of $\mathrm{F}_{1}$ data. Genetics, 39, 767-788.

JINKS, J. L., AND BROAdHuRst, P. L. 1963. Diallel analysis of litter size and body weight in rats. Heredity, 18, 319-336.

JINKS, J. L., AND CONNOLLY, v. 1973. Selection for specific and general response to environmental differences. Heredity, 30, 33-40.

KEARSEY, M. J., AND BARNES, B. W. 1970. Variation for metrical characters in Drosophila populations. II. Natural selection. Heredity, 25, 11-21.

KEARSEY, M. J., AND KOJIMA, K. 1967. The genetic architecture of body weight and egg hatchability in Drosophila melanogaster. Genetics, 56, 23-37.

LAWRENCE, M. J. 1965. Variation in wild populations of Papaver dubium. I. Variation within populations: diallel crosses. Heredity, 20, 183-204.

Mather, K. 1953. The genetical structure of populations. Symp. Soc. Expt. Biol., 7, 66-95.

Mather, K. 1960. Evolution in polygenic systems. Evolution e Genetica. Accad. Nazionale die Lincei., 47, 131-152.

Mather, K. 1973. Genetical Structure of Populations. Chapman and Hall, London.

Mather, K., AND Jinks, J. L. 1971. Biometrical Genetics. Chapman and Hall, London.

PERKINS, J. M., AND JINKS, J. L. 1968. Environmental and genotype-environmental components of variability. III. Multiple lines and crosses. Heredity, 23, 339-356.

simchen, G. 1965. Variation in a dikaryotic population of Collybia velutipes. Amer. Nat., 92, 221-232.

simchen, G. 1966. Fruiting and growth rate among dikaryotic progeny of single wild isolates of Schizophyllum commune. Genetics, 53, 1151-1165.

simchen, G., AND JINKs, J. L. 1964. The determination of dikaryotic growth rate in the Basidiomycete Schizophyllum commune: a biometrical analysis. Heredity, 19, 629-649. 